\title{
PENGARUH LOCUS OF CONTROL, BUDAYA ORGANISASI, KOMITMEN ORGANISASI DAN STRUKTUR AUDIT TERHADAP KINERJA AUDITOR
}

\author{
Dinda Ilmatiara ${ }^{1^{*}}$, Mulia Sosiady ${ }^{2}$, Desrir Miftah ${ }^{3}$ \\ 123 Program Studi Akuntansi, Fakultas Ekonomi dan Ilmu Sosial, UIN Suska Riau, Pekanbaru \\ E-mail: dindatiarailma@gmail.com
}

\begin{tabular}{|c|c|}
\hline Keywords & Abstract \\
\hline $\begin{array}{l}\text { Locus of control, } \\
\text { Organizational Culture, } \\
\text { Organizational } \\
\text { Commitment. } \\
\text { Audit Structure, } \\
\text { Auditor Performance }\end{array}$ & \multirow{3}{*}{$\begin{array}{l}\text { Public trust in auditors or audit firm as an independent party } \\
\text { authorized to audit financial statements is very high. Auditors } \\
\text { who can improve their performance are believed to be capable of } \\
\text { becoming qualified auditors and capable of producing high } \\
\text { quality products. This study aims to analyze the effect of locus of } \\
\text { control, organizational culture, organizational commitment, and } \\
\text { audit structure on auditor performance. The population in this } \\
\text { study were All auditors at level of partners, managers, seniors, } \\
\text { and juniors as well as staff auditors at the Public Accounting } \\
\text { Firm in Pekanbaru. The sampling technique used purposive } \\
\text { sampling. The technique of collecting data using a questionnaire. } \\
\text { This study was tested with multiple regression analysis using the } \\
\text { SPSS } 23 \text { program. The results showed that locus of control, } \\
\text { organizational culture, organizational commitment, and audit } \\
\text { structure had an effect on auditor performance }\end{array}$} \\
\hline Article informations & \\
\hline $\begin{array}{l}\text { Received: } \\
\text { 2020-11-21 } \\
\text { Accepted: } \\
\text { 2020-12-03 } \\
\text { Available on } \\
\text { 2020-12-04 }\end{array}$ & \\
\hline
\end{tabular}

\section{PENDAHULUAN}

Berkembangnya perekonomian didunia bisnis saat ini berdampak pada persaingan perusahaan yang semakin sulit dan kompetitif untuk mempertahankan eksistensi di dunia bisnis dalam skala global. Perkembangan ini mengakibatkan permintaan akan audit laporan keuangan semakin meningkat dan menyebabkan Kantor Akuntan Publik (KAP) harus terus meningkatkan kualitas jasa audit yang di lakukan auditornya. Menurut Mulyadi (2008) "kinerja auditor adalah akuntan publik yang melaksanakan penugasan pemeriksaan (examination) secara objektif atas laporan keuangan suatu perusahaan atau organisasi lain dengan tujuan untuk menentukan apakah laporan keuangan tersebut mmenyajikan secara wajar sesuai prinsip akuntansi yang berlaku umum, dalam semua hal material, posisi keuangan dan hasil usaha perusahaan”.

Kepercayaan masyarakat terhadap auditor ataupun Kantor Akuntan Publik (KAP) sebagai pihak independen yang berwenang dalam mengaudit laporan keuangan sangatlah tinggi. Hal itu berarti keharusan perusahaan go public untuk menerbitkan laporan keuangan 
yang telah diaudit mendorong adanya persaingan digolongan auditor serta berkembangnya profesi tersebut menuntut auditor buat senantiasa tingkatkan kinerjanya, sehingga diyakini sanggup jadi auditor yang bermutu serta sanggup menciptakan produk yang bermutu besar. Standar audit merupakan pedoman bagi auditor dalam menjalankan tugas auditnya. Namun nyatanya banyak auditor yang melakukan penyimpangan terhadap standar dan kode etik yang telah ditetapkan. Hal ini menunjukkan perlu adanya peningkatan kinerja auditor agar terus dapat melakukan jasa audit. Misalnya saja kasus yang terjadi pada Kantor Akuntan Publik (KAP) PricewaterhouseCoopers $(\mathrm{PwC})$ yang melakukan audit dan memberikan opini tidak sesuai dengan kode etik terhadap laporan keuangan PT Asuransi Jiwasraya (Persero) dan PT Asabri (Persero). KAP ini memberikan opini wajar tanpa pengecualian atas laporan keuangan konsolidasian PT Asuransi Jiwasyara (Persero) dan entitas anaknya pada tanggal 31 Desember 2016. Namun pada tanggal 10 Oktober 2018, Jiwasraya justru mengumumkan tak mampu membayar klaim polis JS Saving Plan yang jatuh tempo sebesar Rp802 miliar. Menteri Negara BUMN pun melaporkan dugaan fraud atas pengelolaan investasi Jiwasraya (Maulana,2020)

Kasus di atas memberikan tamparan terhadap kinerja auditor yang masih rendah. Kinerja auditor sangat berarti sebab kinerja yang baik dari seseorang auditor hendak menciptakan laporan keuangan yang bisa di yakin oleh para penggunanya bagaikan dasar pengambilan keputusan. Profesi Akuntan Publik (AP) berperan sebagai penjaga kualitas pelaporan keuangan yang di gunakan oleh publik (stakeholders) sebagai dasar pengambilan keputusan ekonomi. Dengan mengetahui faktor faktor yang berkaitan dengan kinerja auditor di harapkan auditor dapat melaksanakan kegiatan audit dengan lebih efektif dan efesien.

Faktor penting yang berhubungan dengan kinerja auditor pada penelitian ini adalah locus of Control, budaya organisasi, komitmen organisasi dan struktur audit. "Locus of control merupakan salah satu aspek karakteristik yang harus dimiliki oleh individu, dapat dibedakan atas locus of control internal dan locus of control eksternal". (Sarita dan Agustina, 2010). Menurut Rotter (1996) "locus of control merupakan cara pandang seseorang terhadap sesuatu peristiwa apakah ia dapat atau tidak mengendalikan pristiwa yang terjadi padanya". Penelitian Sanjiwani dan Wisadha (2016) locus of control berpengaruh positif pada kinerja auditor, sedangkan penelitian Kusnandi (2015) menunjukkan locus of control berpengaruh negatif pada kinerja auditor.

Menurut Wood et al (2001), "budaya organisasi merupakan suatu sistem yang di percayai dan nilai yang di kembangkan oleh organisasi dimana hal ini menuntut perilaku dari anggota itu sendiri”. Menurut penelitian Wahidi, et al (2020); Prabayanthi dan Widhayani 
(2018) budaya organisasi berpengaruh positif terhadap kinejra auditor, tapi berbeda dengan penelitian Trisnaningsih (2007) yang menemukan bahwa budaya organisasi tidak berpengaruh pada kinerja auditor.

Komitmen organisasi menurut Hana dan Firnanti (2013) merupakan "menunjukan loyalitas yang di miliki individu terhadap organisasinya serta menunjukan bagaiman anggota organisasi dapat memberikan kontribusi dalam menciptakan kesuksesan organisasi”. Putri (2015) menyatakan bahwa "adanya komitmen organisasi yang di miliki seseorang akan memberikan pengaruh positif bagi organisasi karena dengan komitmen organisasi yang tinggi akan mempunyai rasa ikut memiliki organisasi tersebut".

Selanjutnya Browrin (1998) dalam Fanani (2008) “menyatakan struktur audit sebagai sebuah pendekatan sistematis terhadap auditing yang di karakteristikan oleh langkah-langkah penentuan audit, prosedur rangkaian logis, keputusan, dokumentasi untuk membantu auditor dalam melakukan audit". Struktur audit membantu auditor senior dalam menyajikan perintah kepada staf auditnya mengenai pekerjaan yang harus dilakukan sehingga akan lebih mudah serta akan meningkatkan kinerja auditor.

Penelitian ini bertujuan untuk menguji locus of control, budaya organisasi komitmen organisasi dan struktur audit terhadap kinerja auditor. Penelitian sebelumnya Prabayanthi \& Widhiyani (2018) menhuji Pengaruh Profesionalisme, Budaya Organisasi dan Komitmen Organisasi pada Kinerja Auditor pada KAP di Provinsi Bali. Penelitian mengembangkan penelitian tersebut dengan menambahhkan locus of control dan struktur audit. Penelitian ini dilakukan pada auditor pada KAP di Kota Pekanbaru.

\section{PENGEMBANGAN HIPOTESIS}

\section{Pengaruh Locus of Control terhadap Kinerja Auditor}

Menurut Sanjiwani dan Wishada, locus of control berpengaruh terhadap kinerja auditor dengan nilai pengaruh positif. Ketika Locus of control yang semakin baik maka mengakibatkan kinerja yang dihasilkan juga semakin baik. Locus of control didefinisikan bagaikan anggapan seorang tentang sumber nasibnya. Sebagian orang yakin kalau mereka merupakan penentu dari takdir mereka sendiri. Sebagian yang lain memandang kalau apa yang terjalin pada diri mereka diakibatkan oleh keberuntungan ataupun peluang. Riset yang telah dilakukan Ayudiati (2010) mengatakan kalau locus of control mempengaruhi positif serta signifikan terhadap kinerja karyawan.

\section{$\mathrm{H}_{1}$ : Locus of control berpengaruh positif terhadap kinerja auditor.}


PENGARUHLOCUS OF CONTROL, BUDAYA ORGANISASI, KOMITMEN ORGANISASI DAN STRUKTUR AUDIT TERHADAP KINERJA AUDITOR

\section{Pengaruh Budaya Organisasi Terhadap Kinerja Auditor}

Budaya organisasi ialah satu faktor berarti dalam industri yang hakikatnya menuju pada perilaku- perilaku yang dikira pas, mengikat serta memotivasi tiap orang yang terdapat didalamnya. Budaya organisasi yang besar bisa tingkatkan kinerja auditor dengan motivasi kerja yang besar pula. Budaya organisasi membagikan sugesti supaya bisa menuntaskan tugas dengan sukses serta membagikan keuntungan untuk dirinya sendiri. Pada penelitian Yuskar dan Devisia (2011), Prabayanthi dan Widhiyani (2018), Wahidi, et al (2020) menghasilkan bahwa budaya organisasi berpengaruh terhadap kinerja auditor serta Trisaningsih (2007) menyatakan bahwa budaya organisasi tidak berpengaruh terhadap kinerja auditor.

\section{$\mathrm{H}_{2}$ : Budaya organisasi berpengaruh positif terhadap kinerja auditor.}

\section{Pengaruh Komitmen Organisasi Terhadap Kinerja Auditor}

Penelitian dari Trisnaningsih (2007), Prabayanthi dan Widhiyani (2018) serta Sanjiwan (2016) menyebutkan bahwa komitmen organisasi berpengaruh positif terhadap kinerja auditor. Komitmen yang tepat akan membuat seseorang memiliki sifat loyalitas yang tinggi terhadap pekerjaannya dan pasti akan memberikan dampak yang positif terhadap kinerja suatu pekerjaan. Hal ini menunjukkan bahwa semakin tinggi komitmen seorang auditor akan semakin baik.

\section{$\mathrm{H}_{3}$ : Komitmen organisasi berpengaruh positif terhadap kinerja auditor.}

\section{Pengaruh Struktur Audit Terhadap Kinerja Auditor}

Penelitian Sitio dan Anisykurlillah (2014), Winidiantari dan Widhiyani (2015) menyatakan bahwa struktur audit berpengaruh positif terhadap kinerja auditor. Pemakaian struktur audit bisa menolong auditor dalam melakukan tugasnya jadi lebih baik, sehingga bisa tingkatkan kinerja auditor. Hasil penelitian Bamber et al. (1989) "menunjukkan bahwa kantor akuntan publik yang menggunakan struktur audit akan meningkatkan kinerja auditor, sebaliknya kantor akuntan publik yang tidak menggunakan struktur audit memiliki potensi meningkatnya konflik peran dan ketidakjelasan peran yang dirasakan oleh staf auditnya".

\section{$\mathrm{H}_{4}$ : Struktur audit berpengaruh positif terhadap kinerja auditor.}

\section{METODE PENELITIAN}

Riset ini memanfaatkan metode penelitian kuantitatif. Menggunakan data yang diperoleh melalui kuesioner yang disebarkan kepada semua auditor yang bekerja pada 
Kantor Akuntan Publik yang berada di kota Pekanbaru. Metode pengumpulan data yang digunakan dalam penelitian ini adalah dengan mengantarkan kuisioner kepada seluruh KAP. Locus of Control, budaya organisasi, komitmen organisasi dan struktur audit sebagai variabel independen. Variabel dependen pada riset ini adalah kinerja auditor. Populasi dalam riset ini ialah semua auditor yang bekerja pada kantor akuntan publik di Pekanbaru yang terdaftar pada direktori Kantor Akuntan Publik yang dikeluarkan oleh Ikatan Akuntan Indonesia yakni ada 8 Kantor Akuntan Publik dan hanya ada 7 Kantor Akuntan Publik yang dapat diteliti, terdapat 1 Kantor Akuntan Publik yang tidak berpartisipasi karena Kantor Akuntan Publik yang bersangkutan dikonfirmasi telah tutup. Adapun sampel pada penelitian ini berasal dari 40 orang auditor. Teknik pengambilan sampel menggunakan purposive sampling (Sugiyono 2013:122) yaitu "teknik penentuan sampel dengan kriteria-kriteria tertentu dalam pengambilan sampel sesuai dengan tujuan penelitian”. Kriterianya yaitu: auditor yang telah bekerja minimal 1 tahun dan pendidikan terakhir minimal D3.

\section{Definisi Variabel dan Pengukurannya}

Kinerja auditor (KA) diukur dengan mengembangkan instrument yang dikembangkan oleh Mayer dan Allen (1984) dalam Trinaningsih (2007). Variabel ini memiliki 5 indikator antara lain: kemampuan, komitmen, profesi, motivasi dan kepuasan kerja.Untuk menilai kinerja auditor maka responden akan memberikan penilaian dengan memilih salah satu dari 5 poin skala likert. Menurut Sugiyono (2013) "skala likert digunakan untuk mengukur sikap, pendapat, persepsi seorang atau kelompok orang tentang fenomena sosial".

Locus of Control( LOC) merupakan metode pandang seorang terhadap sesuatu kejadian apakah seorang itu bisa ataupun tidak bisa mengatur kejadian yang terjalin kepadanya. Adapun variabel locus of control diukur dengan mengadopsi instrumen yang dikembangkan oleh Rotter (1966) dalam Maturidi (2016). Indikator locus of control terbagi dua, locus of control eksternal dan locus of cotrol internal, yang mana indikatornya adalah sebagai berikut: internal locus of control dengan indikator yang (pertama) seluruh yang dicapai orang hasil dari usaha sendiri, (kedua) jadi pemimpin sebab keahlian sendiri, (ketiga) keberhasilan orang sebab kerja keras, (keempat) seluruh yang diperoleh orang bukan sebab keberuntungan. Sebaliknya penanda eksternal locus of control yang (pertama) kegagalan yang dirasakan orang sebab ketidakjujuran, (kedua) perencanaan jauh ke depan merupakan pekerjaan yang percuma, (ketiga) peristiwa yang dirasakan dalam hidup didetetapkan oleh orang yang berkuasa, serta yang (keempat) kesuksesan orang sebab aspek nasib. Untuk 
menilai pengaruh locus of control terhadap kinerja auditor maka responden akan memberikan penilaian dengan memilih salah satu dari 5 poin skala likert.

Budaya organisasi (BO) sebagai pola pemikiran, perasaan dan tindakan dari suatu kelompok sosial yang membedakan dengan kelompok sosial lain. Variabel ini diukur dengan menggunakan instrument yang dikembangkan oleh Hofstede (1990) dalam Trinaningsih (2007). Dengan indikator budaya organisasi yang berorientasi pada orang dan budaya organisasi yang berorientasi pekerjaan. Untuk menilai pengaruh budaya organisasi terhadap kinerja auditor maka responden akan memberikan penilaian dengan memilih salah satu dari 5 poin skala likert.

Komitmen Organisasi (KO) menurut Luthans (2992) "merupakan keinginan yang kuat untuk menjadi anggota dalam suatu kelompok, kemauan usaha yang tinggi untuk organisasi and suatu keyakinan tertentu dan penerimaan terhadap nilai-nilai dan tujuantujuan dari organisasi”. Variabel ini diukur dengan menggunakan instrumen yang dikembangkan oleh Mayer dan Allen (1984) dalam Trinaningsih 2007. Variabel ini memiliki dua indikator, Indikator komitmen organisasi adalah Komitmen organisasi affective dan komitmen continuance. Untuk menilai pengaruh komitmen organisasi terhadap kinerja auditor maka responden akan memberikan penilaian dengan memilih salah satu dari 5 poin skala likert.

Struktur Audit (SA) ialah perlengkapan ataupun lapisan prosedur buat menolong auditor melaksanakan aktivitas audit. Struktur audit di susun sedemikian rupa setelah itu di laksanakan sehingga aktivitas audit tercapai. Variabel ini diukur dengan menggunakan instrumen yang dikembangkan dari Fanani (2008) dalam Yulistiani (2015). Indikator struktur audit adalah prosedur ataupun ketentuan dalam penerapan audit, petunjuk ataupun instruksi penerapan audit, kepatuhan atas keputusan yang diresmikan, pemakaian media transformasi serta kebijakan audit yang kompherensif serta terintegritas. Untuk menilai struktur audit maka responden akan memberikan penilaian dengan memilih salah satu dari 5 poin skala likert

\section{Metode Analisis Data}

\section{Analisis Regresi Linier Berganda}

Hipotesis dalam riset ini uji dengan analisis regresi linier berganda . Menganalisa pengaruh variabel - variabel independen terhadap variabel dependen. Setelah itu dicoba pengecekan dengan melaksanakan plot informasi buat memandang terdapatnya informasi linear ataupun tidak linear . Persamaan regresi linier merupakan bagaikan berikut: 


$$
\mathrm{KA}=\alpha+\beta 1 \mathrm{LOC}+\beta 2 \mathrm{BO}+\beta 3 \mathrm{KO}+\beta 4 \mathrm{SA}+\mathrm{e}
$$

\section{Uji Determinasi}

Koefisien determinasi $\left(\mathrm{R}^{2}\right)$ mengukur seberapa jauh keahlian model dalam menerangkan alterasi variabel dependen. Nilai koefisien determinasi merupakan antara nol serta satu. Nilai R2 yang kecil berarti keahlian keahlian variabel variabel independen dalam menarangkan alterasi variabel dependen amat terbatas. Ghozali (2013) menyatakan bahwa "nilai yang mendekati satu berarti variabel berarti variabel-variabel independen memberikan hampir semua informasi yang dibutuhkan untuk memprediksi variasi variabel dependen".

\section{Uji Statistik F}

Uji F di gunakan pada dasarnya buat menampilkan apakah seluruh variabel- variabel independen memiliki pengaruh secara bersama- sama terhadap variabel dependen. Uji $F$ di jalani dengan menyamakan $\mathrm{F}$ hitung terhadap $\mathrm{F}$ tabel, bila $\mathrm{F}$ hitung $>\mathrm{F}$ tabel, hingga Hipotesis diterima. Maksudnya informasi yang terdapat bisa meyakinkan kalau seluruh variabel independen berpengaruh terhadap variabel dependen. Dan menunjukkan model penelitian baik dan dapat digunakan untuk penujian hipotesis. Dan sebaliknya.

\section{Uji Koefisien Regresi Parsial (Uji-t)}

Uji statistik t pada dasarnya menampilkan berapa jauh pengaruh satu variabel independen secara individual dalam menerangkan variabel dependen. Pengujian dicoba dengan memakai significance tingkat $0,05(\alpha=5 \%)$. Penerimaan ataupun penolakan hipotesa dicoba dengan kriteria bila nilai thitung $>$ ttabel, maka hipotesa terima. Ini berarti kalau secara parsial variabel independen tersebut memiliki pengaruh yang signifikan terhadap variabel dependen. Serta kebalikannya.

\section{HASIL PENELITIAN DAN PEMBAHASAN}

\section{Statistik Deskriptif}

Uji statistik deskriptif memberikan gambaran atau deskripsi suatu data yang dilihat dari nilai rata-rata (mean), standar deviasi, varian, maksimum, dan minimum. Statistik deskriptif penelitian dapat di lihat pada tabel 1 sebagai berikut : 


\section{Tabel 1}

\section{Statistik Deskriptif}

\begin{tabular}{lccccc}
\hline & N & Minimum & Maximum & Mean & Std. Deviation \\
\hline Kinerja Auditor (KA) & 40 & 44 & 58 & 51.88 & 3.275 \\
Locus of Control (LOC) & 40 & 19 & 37 & 31.78 & 4.7201 \\
Budaya Organisasi (BO) & 40 & 24 & 37 & 31.03 & 3.278 \\
Komitmen Organisasi (KO) & 40 & 43 & 60 & 50.60 & 4.505 \\
Struktur Audit (SA) & 40 & 16 & 25 & 21.05 & 2.012 \\
Valid N (listwise) & 40 & & & & \\
\hline
\end{tabular}

Sumber: Olah data dengan menggunakan SPSS

\section{Pengujian Hipotesis dan Pembahasan}

Pengujian hipotesis menggunakan analisis regresi linier berganda bertujuan untuk mengetahui besarnya pengaruh locus of control, budaya organisasi, komitmen organisasi dan struktur audit pada kinerja auditor. Persamaan matematis untuk hubungan yang dihipotesiskan dapat dirumuskan sebagai berikut:

\section{Tabel 2}

\section{Hasil Uji Statistik t}

\begin{tabular}{|c|c|c|c|c|c|}
\hline \multirow[b]{2}{*}{ Variabel } & \multicolumn{2}{|c|}{$\begin{array}{l}\text { Unstandardized } \\
\text { Coefficients }\end{array}$} & \multirow{2}{*}{$\begin{array}{l}\text { Standardized } \\
\text { Coefficients } \\
\text { Beta }\end{array}$} & \multirow[b]{2}{*}{$\mathrm{t}$} & \multirow[b]{2}{*}{ Sig. } \\
\hline & B & Std. Error & & & \\
\hline 1 (Constant) & 17.267 & 4.293 & & 4.022 & .000 \\
\hline Locus of Control (LOC) & .440 & .075 & .634 & 5.845 & .000 \\
\hline Budaya Organisasi (BO) & .267 & .114 & .267 & 2.338 & .025 \\
\hline Komitmen Organisasi(KO) & .132 & .062 & .181 & 2.132 & .040 \\
\hline Struktur Audit (SA) & .271 & .129 & .166 & 2.092 & .044 \\
\hline a. Dependent Variable: Kinerj & Audito & & & & \\
\hline
\end{tabular}

Sumber: Olah data dengan menggunakan SPSS

Berdasarkan Tabel 2 maka diperoleh persamaan regresi linier berganda sebagai berikut.

$$
\mathrm{KA}=17,267+0,440 \mathrm{LOC}+0,267 \mathrm{BO}+0,132 \mathrm{KO}+0,271 \mathrm{SA}+\mathrm{e}
$$

Pengujian ini adalah untuk menguji bahwa locus of control, budaya organisasi, komitmen organisasi, dan struktur audit secara bersama memiliki perngaruh terhadap kinerja auditor di KAP Kota Pekanbaru. Ditunjukkan dari hasil pengujian yang diperoleh nilai $\mathrm{F}$ hitung sebesar 33,302 pada tingkat signifkansi 0.000, artinya dapat dipastikan bahwa $\mathrm{F}$ hitung lebih besar daripada $\mathrm{F}$ tabel $(2,64)$. 


\section{Hasil pengujian hipotesis 1 : Locus of control mempengaruhi kinerja auditor}

Hipotesis pertama (H1) memiliki nilai t hitung lebih besar dari t tabel yakni diketahui $t$ hitung $(5,845)>\mathrm{t}$ tabel $(2,03011)$ dan sig. $(0.000<0,05)$. ini berarti H0 ditolak dan Ha diterima. Jadi locus of control memiliki pengaruh positif terhadap kinerja auditor karena ketika locus of control yang semakin baik maka mengakibatkan kinerja yang dihasilkan juga semakin baik. Nilai koefisien regresi variabel locus of control (X1) adalah 0,440 dan bertanda positif. Hal ini berarti bahwa setiap perubahan satu satuan pada variabel locus of control (X1) dengan asumsi variabel lainnya tetap, maka perubahan yang diperoleh pada variabel kinerja auditor $(\mathrm{Y})$ adalah sebesar $0,440 \mathrm{ke}$ arah positif. Artinya semakin tinggi locus of control yang di miliki auditor KAP Kota Pekanbaru maka semakin tinggi pula kinerja Auditor yang di hasilkan sehingga akan menghasilkan produk yang berkualitas. Auditor yang memiliki Locus Of Control lebih termotivasi buat menuntaskan pekerjaanpekerjaan mereka, sehingga memunculkan kepuasan serta hendak terus menjadi tingkatkan kinerja mereka.

Hasil penelitian ini konsisten dengan penelitian yang dilakukan oleh Rahayu dan Badera (2017), Maturidi (2016), Kusnandi (2015), Meliana dan Yuniarto (2014) serta Julianingtyas (2012) yang menyatakan bahwa locus of control berpengaruh terhadap kinerja auditor.

\section{Hasil pengujian hipotesis 2 : Budaya organisasi mempengaruhi kinerja auditor}

Hipotesis kedua (H2) memiliki nilai t hitung lebih besar dari t tabel yakni diketahui $\mathrm{t}$ hitung $(2,338)>\mathrm{t}$ tabel $(2,03011)$ dan sig. $(0.025<0,05)$. Hasil ini menunjukkan bahwa H0 ditolak dan Ha diterima. Jadi dapat disimpulkan budaya organisasi memiliki pengaruh positif terhadap kinerja auditor karena budaya organisasi (corporate culture) merupakan selaku ketentuan main yang terdapat dalam industri yang jadi pegangan untuk sumberdaya manusia industri dalam melaksanakan kewajiban serta nilai- nilai buat berperilaku dalam organisasi. Nilai koefisien regresi variabel budaya organisasi $\left(\mathrm{X}_{2}\right)$ adalah 0,267 dan bertanda positif. Hal ini berarti bahwa setiap perubahan satu satuan pada variabel budaya organisasi $\left(\mathrm{X}_{2}\right)$ dengan asumsi variabel lainnya tetap, maka perubahan yang diperoleh pada variabel kinerja auditor (Y) adalah sebesar 0,267 satuan dengan arah positif. Artinya semakin tinggi budaya organisasi yang di terapkan pada KAP kota Pekanbaru maka semakin tinggi pula kinerja auditor.

Hasil penelitian ini konsisten dengan penelitian Prabayanthi dan Widhiyani (2018), Sitio dan Anisykurlillah (2014) serta Yuskar dan Devisia (2011) yang menemukan kalau budaya organisasi mempengaruhi terhadap kinerja auditor. Hasil ini menampilkan kalau tiap 
industri tentu mempunyai arti sendiri terhadap kata budaya itu sendiri, yang meliputi: bukti diri, pandangan hidup, etos, budaya, pola sikap, eksistensi, ketentuan, filosofi, tujuan spirit, sumber data, style serta visi perusahaan.

\section{Hasil pengujian hipotesis 3 : Komitmen organisasi mempengaruhi kinerja auditor}

Hipotesis ketiga (H3) memiliki nilai t hitung lebih besar dari t tabel yakni diketahui $t$ hitung $(2,132)>\mathrm{t}$ tabel $(2,03011)$ dan sig. $(0.040<0,05)$ Artinya H0 ditolak Ha diterima. Jadi Komitmen Organisasi memiliki pengaruh positif terhadap kinerja auditor karena terus menjadi besar rasa komitmen organisasi bisa tingkatkan kinerja. Dengan meningkatkan rasa aman didalam organisasinya hendak membuat bahagia terletak dalam organisasinya teruji dalam riset ini point dimana rasa menuntaskan tugas dengan bahagia hati, diakui, serta rasa mempunyai nilai yang tinggi Nilai koefisien regresi variabel Komitmen Organisasi $\left(\mathrm{X}_{3}\right)$ adalah 0,132 dan bertanda positif. Hal ini berarti bahwa setiap perubahan satu satuan pada variabel komitmen organisasi $\left(\mathrm{X}_{3}\right)$ dengan asumsi variabel lainnya tetap, maka perubahan yang diperoleh pada variabel kinerja auditor (Y) adalah sebesar 0,132 ke arah positif. . Artinya semakin tinggi rasa Komitmen organisasi yang di miliki auditor KAP kota Pekanbaru maka semakin mempengaruhi pula kinerjanya.

Hasil penelitian ini konsisten dengan penelitian Prabayanthi dan Widhiyani (2018), Sanjiwan (2016) dan Trisnaningsih (2007). Komitmen organisasi merupakan salah satu elemen yang penting dalam diri seorang auditor. Dimana perasaan memilki untuk turut serta berpartisipasi dalam kemajuan organisasi dapat diwujudkan dengan menjaga sikap dari halhal yang dapat menurunkan kepercayaan, atau menimbulkan pencitraan buruk dari publik.

\section{Hasil pengujian hipotesis 4 : Stuktur organisasi mempengaruhi kinerja auditor}

Hipotesis keempat (H4) memiliki nilai t hitung lebih besar dari t tabel yakni diketahui t hitung 2,092) $>\mathrm{t}$ tabel $(2,03011)$ dan sig. $(0.044<0,05)$ Artinya H0 ditolak Ha diterima. Nilai koefisien regresi variabel struktur audit $\left(\mathrm{X}_{4}\right)$ adalah 0,271 dan bertanda positif. Hal ini berarti bahwa setiap perubahan satu satuan pada variabel struktur audit $\left(\mathrm{X}_{4}\right)$ dengan asumsi variabel lainnya tetap, maka perubahan yang diperoleh pada variabel kinerja auditor (Y) adalah sebesar 0,271 ke arah positif. Jadi Struktur Audit memiliki pengaruh positif terhadap kinerja auditor sebab Pemakaian struktur audit bisa menolong auditor dalam melakukan tugasnya jadi lebih baik, sehingga bisa tingkatkan kinerja auditor.

Hasil penelitian ini konsisten dengan penelitian Winidiantari dan Widhiyani (2015) serta Sitio dan Anisykurlillah (2014) yang menemukan bahwa "penggunaan pendekatan struktur audit memiliki keuntungan yaitu mendorong efektivitas, mendorong efisiensi, 
mengurangi litigasi yang dihadapi KAP, mempunyai dampak positif terhadap konsekuensi sumber daya manusia, dan dapat memfasilitasi diferensiasi pelayanan atau kualitas sehingga diduga dapat meningkatkan kinerja auditor".

\section{SIMPULAN}

Riset ini betujuan buat menguji pengaruh variabel locus of control, budaya organisasi, komitmen organisasi serta struktur audit terhadap kinerja auditor( Riset Empiris Pada Auditor yang bekerja pada Kantor Akuntan Publik( KAP) di Kota Pekanbaru). Bersumber pada pada informasi yang sudah dikumpulkan serta hasil pengujian yang sudah dicoba terhadap kasus dengan memakai analisis regresi, hingga bisa diambil kesimpulan kalau locus of control, budaya organisasi, komitmen organisasi serta struktur audit mempengaruhi terhadap kinerja auditor.

Beberapa keterbatasan yang dirasakan dalam penelitian ini antara lain yaitu pertama, responden yang digunakan dalam riset ini masih terbatas serta cuma terfokus pada Auditor yang bekerja di Kantor Akuntan Publik (KAP) yang terdapat di Pekanbaru serta terdaftar disitus Institut Akuntan Publik Indonesia (IAPI) pada tahun 2019 sehingga perlu selalu diperbaharui dengan data yang terkini. Kedua, penelitian yang dilakukan terhadap kinerja auditor di Kota Pekanbaru hanya menggunakan beberapa variabel, yaitu locus of control, budaya organisasi, komitmen organisasi, dan struktur audit. Ketiga, penyebaran kuisoner pada waktu yang kurang efektif, yakni pada awal tahun. Dimana pada waktu tersebut tingkat kesibukan auditor sangat tinggi sehingga tidak dapat melakukan wawancara dalam penelitian dan adanya jangka waktu dalam pengembalian kuisoner pada setiap kap (21 Januari- 4 Februari 2020)

\section{REFERENSI}

Agues, S. (2012). Auditing (Pemeriksaan Akuntan) Oleh Kantor Akuntan Publik. Buku 1, Edisi 4. Salemba Empat. Jakarta.

Arumsari, A. L. (2014). Pengaruh Profesionalisme Auditor, Independensi Auditor, Etika Profesi, Budaya Organisasi, Dan Gaya Kepemimpinan Terhadap Kinerja Auditor Pada Kantor Akuntan Publik di Bali. Tesis. Universitas Udayana. Denpasar.

Agustia, D. J. \& Sarita. (2010). Pengaruh Gaya Kepemimpinan Situasional, Motivasi Kerja, Locus Of Control Terhadap Kepuasan Kerja Dan Prestasi Kerja Auditor. Skripsi. Universitas Airlangga.

Ayudiati, S. E (2010). Analisis Pengaruh Locus Of Control terhadap Kinerja Dengan Etika Islam Sebagai Variabel Moderating. Skripsi. Universitas Diponogoro Semarang. 
DENGARUHLOCUS OF CONTROL, BUDAYA ORGANISASI, KOMITMEN ORGANISASI DAN STRUKTUR

AUDIT TERHADAP KINERJA AUDITOR

Fanani, ZZaenal, (2008). Pengaruh Struktur Audit, Konflik Peran Dan Ketidak Jelasan Peran Terhadap Kinerja Auditor. Jurnal Akuntansi Dan Keuangan Indonesia vol 5 no 2 desember 2008

Ghozali, I. (2013). Aplikasi Analisis Multivariate Dengan Program IBM SPSS 23. Semarang: Badan Penerbit Universitas Diponegoro.

Hana, E., \& dan Friska F. (2013). Faktor-faktor yang Mempengaruhi Auditor Kinerja”. Jurnal Bisnis dan Akuntansi. Vol 15 No. 1. STIE Trisakti. Jakarta.

Kusnadi, dan Dewa, G. (2015). Pengaruh Profesionalisme dan Locus Of Control Terhadap Kinerja Auditor Di Kantor Akuntan Publik Provinsi Bali, E-jurnal Akuntansi Universitas Udayana (hlm. 276-291).

Maulana,A.G (2020) Kemenku Ancam Sanksi Tegas KAP yang Terlibat Kasus Jiwasraya dan Asabri. https://ayobandung.com/read/2020/01/15/76501/kemenku-ancam-sanksitegas-kap-yang-terlibat-kasus-jiwasraya-dan-asabri

Maturidi, A. (2016). Analisis Pengaruh Independensi Dan Locus Of Control Terhadap Kinerja Auditor Internal (Studi Kasus Pada Inspektorat Lombok Timur). Jurnal Ilmiah Rinjani, Vol.4.

Mulyadi. (2014). Auditing. Buku 1. Edisi ke-6. Jakarta. Salemba Empat.

Meiliana, M. D., \& Arif S. (2014). Pengaruh Locus Pengendalian, Komitmen Profesi, Budaya Organisasi, Sistem Kompensasi Serta Sikap Indepedensi Terhadap prilaku Auditor dengan Menghadapi Konflik Audit. Jurnal Reksa: Rekayasa Kuangan, Syariah dan Audit.Vol 3, No. 1

Nuraini, L. (2016). Pengaruh Indepedensi, Gaya Kepemimpinan Dan Budaya Organisasi Terhadap Kinerja Auditor (Studi Empiris Pada Kap Yogjakarta Dan Solo). Skripsi. Universitas Negri Yogyakarta.

Prabayanthi, P. A., \& Ni L. S. W. (2018). Pengaruh Profesionalisme, Budaya Organisasi dan Komitmen Organisasi pada Kinerja Auditor. E- jurnal Akuntansi Universitas Udayana (hlm. 1059-1084).

Putri, K. M. D., \& Suputra, I. D. G. D. (2013). Pengaruh Indepedensi, Profesionalisme dan Etika Profesi Terhadap Kinerja Auditor Pada KAP Di Bali. E- jurnal Akuntansi Universitas Udayana.

Pratiwi, F. H. (2017). Pengaruh Locus Of Control, Gaya Kepemimpinan, Budaya Organisasi, Serta Pengaruh Pemahaman Good Governance Terhadap Kinerja Auditor (Studi Empiris Pada Kantor Akuntan Publik Di Kota Surakarta Dan DIY. Skripsi. Universitas Muhammadiyah Surakarta.

Rahayu, Ni M.M.S \& Badera, D. N. (2017). Lokus Pengaruh Pengendalian Internal, Motivasi Kerja, Gaya Kepemimpinan Transfornmal, Komitmen Organisasi Pada Kinerja Auditor. E-Jurnal Akuntansi. Vol. 15 No 3. Universitas Udayana 
Sugiyono. (2014). Metode Penelitiann Bisnis (Pendekatan Kuantitatif, Kualitatif, dan R\&D). Bandung. Alfabeta.

Sujarweni, V. Wiratna. Metodologi Penelitian Bisnis dan Ekonomi Pendekatan Kuantitatif. Yogyakarta. Pustaka Baru Pres.

Sitio, R. D. (2014). Pengaruh Pemahaman Good Governance, Gaya Kepemimpinan, Budaya Organisasi, Dan Struktur Audit Terhadap Kinerja Auditor. Studi Empiris Pada KAP Di Kota Semarang. Accounting Analysis Journal.

Sanjiwani, D. M. P., \& Wisadha, I. G. S. (2016). Pengaruh Locus Of Control, Gaya Kepemimpinan dan Komitmen Organisasi pada Kinerja Auditor Kantor Akuntan Publik, E-jurnal Akuntansi Universitas Udayana.

Trisnaningsih, S. (2007). Independensi Auditor Dan Komitmen Organisasi Sebagai Mediasi Pengaruh Pemahaman Good Governance, Gaya Kepemimpinan Dan Budaya Organisasi Terhadap Kinerja Auditor. Simposium Nasional Akuntansi X.

Wahidi, U., Hardi, \& Devi, D. S. (2020). Pengaruh Independensi, Gaya Kepemimpinan Dan Budaya Organisasi Terhadap Kinerja Auditor : Komitmen Organisasi Sebagai Mediasi. CURRENT: Jurnal Kajian Akuntansi Dan Bisnis Terkini, 1(2), 219-238. https://doi.org/10.31258/jc.1.2.219-238

Winidiantari, P. N., \& Widhiyani, N. L. S. (2015). Pengaruh Konflik Peran, Ketidakjelasan Peran, Standar Audit, Motivasi Dan Kepuasan Kerja Terhadap Kinerja Auditor. Ejurnal akuntansi, Vol. 12 No. 2.

Yulistiani. (2015). Pengaruh Struktur Audit, Konflik Peran, Ketidakjelasan Peran Dan Komitmen Organisasi Terhadap Kinerja Auditor. Skripsi. Universitas Pasundan.

Yuskar \& Selly, D. (2011). Pengaruh Indepedensi Auditor, Komitmen Organisasi, Pemahaman GOC, Integritas Auditor, Budaya Organisasi Dan Etos Kerja Terhadap Kinerja Auditor. Jurnal dan prosiding SNA. Vol. 14

Http://www.iapi.or.id/iapi/directory 